\title{
Comic-Con: Can Comics of the Constitution Enable Meaningful Learning in Political Science? - Corrigendum
}

\section{Katharine A. Owens}

Victor Eno

Jocelyn Abrams

Danielle Bedney

doi: https://doi.org/10.1017/S1049096519001008 Published online by Cambridge University Press, 10 July 2019.

On page 164 of the article, we use language that is imprecise when we conclude, "this analysis of 71 American 18 - to 22 -year-olds indicates that youth gain more knowledge when they view a comic panel of the Constitution than they do from reading the text of the document."

We did not intend to imply that individuals comparatively gain more from viewing the comic than from reading the text. As indicated in the methodology section, we do not test each method (comic and text) on the sample, but instead split the sample for testing.

It is more precise to state our results as we do in the abstract on page 161: "Respondents viewing the comic of congressional duties experienced statistically significant gains in pretest to posttest mean knowledge scores. Respondents viewing the text also experienced an increase in mean scores pretest to posttest; however, these changes were smaller and not statistically significant." Fortunately, our error in language does not impact the conclusions we drew from the analyses performed in our research and described in this article. "

\section{REFERENCE}

Owens, Katharine A., Victor Eno, Jocelyn Abrams, and Danielle Bedney. “Comic-Con: Can Comics of the Constitution Enable Meaningful Learning in Political Science?” PS: Political Science \& Politics 53(1) 161-166. doi: https://doi.org/10.1017/S1049096519001008 